\title{
Challenges and Resources in CPD for In-Service Teachers: Establishing Communities of Inquiry
}

\author{
PriskaPramastiwi \\ priskapram@gmail.com \\ Anita Lie \\ SantiWidiati \\ Trianawaty Lie \\ Widya Mandala Catholic University Surabaya \\ Surabaya, Indonesia
}

\begin{abstract}
As teachers are reflective pedagogical thinkers, in-service continuing professional development (CPD) is imperative. Previous studies reveal that insufficient school support and teacher's incapacity to reflect on their practices recurrently hamper CPD. However, biographical inquiries, encompassing in-service challenges and resources employed in CPD, are scant. This study investigated (a) thechallenges teachers face in improving their professionalism, and (b) the perceived positive influence of engaging in a community of inquiry (CoI) on professional development. We conducted an in-depth analysis of fifteen Indonesian teachersat differing professional stages. Data from reflective essays and semi-structured interviews disclosed that the perennial challenges faced are time management and the lack of access to a wider learning community. A notable finding is thatonly a small minority of teachers soughtexternal resources or indulged in a reflective inquiry due to a possible overreliance on the top-down structured CPD scheme within the school management. Upon partaking in an online CoI in a MOOC on ICT, the participants confirmed the easy integration of novelideas and repurposed the suggested digital tools to alleviate daily teaching challenges. Moreover, the teachers harnessed their metacognitive skills to immerse in collegial discussion with a diverse professional network, and collaborativelyconstruct understanding.
\end{abstract}

Keywords: continuing professional development; challenges, community of inquiry; MOOC

\section{Introduction}

Teacher quality is the key to improving students' achievement. However, in many countries including Indonesia, the teaching profession is still characterized by its low quality and levels of competence, which remains unchanged after a decade of education reforms. In many school systems, teachers are seldom given opportunities to undergocontinuing professional development (CPD). They have long hours of teaching (more than 28 periods of teaching in a week), demanding paperwork, student counseling, and various extra-curricular work. On the upside, despite the absence of nationwide standardizes strategy, a few school systems have demonstrated a commitment to improving their teacher quality and engaging their teachers in continuous professional development.

Schleicher (2015) reported that teachers in Indonesia attending teacher development program of which district office and the school supervisors involved feel more confident and better prepared. While improving 
teacher quality is underway in several projects designed to enhance teacher education and certification programs in Indonesia, it would take several years before school systems could provide evidence that they are developing effective teachers (de Koning, 2012, Chang et al. 2014).

In some countries, CPD is successful (Schleicher, 2015), and in some others, CPD is ineffective because, among others, they are top-down, a "fix-it" approach, teachers are reluctant, prescriptive ideas, one-sizefits-all techniques, fixed and untimely delivery methods, little or no follow-up, decontextualized programs, lack of proper evaluation, pedagogical (child-centered) instruction(Díaz-Maggioli, 2014). Walter and Briggs (2012) reported studies of teacher professional development showing that successful CPD introduces practical knowledge and skills to help students achieve their learning outcomes. Schleicher (2015) reported that teachers in Indonesia attending teacher development program of which district office and the school supervisors involved feel more confident and better prepared. These findings are consistent with Ebersöhn et al. (2015) who find that school intervention for in-service teachers in highrisk and high-need schools in South Africa motivated teachers to gain competency and optimism, demonstrate management skills, and make valuable contributions in a group.

Not all teacher development programs are effective. Chang et al. (2014) argued that one-off seminars and in-service short courses in cascade fashion did not make development programs in Indonesia effective. Czerniawski (2011) reported that teachers in England, Norway and Germany joining professional development programs were dissa- tisfied with the quality and outcomes. DíazMaggioli (2014) identified eleven ineffective factors of professional development, they are top-down decision-making, a "fixit” approach, lack of program ownership among teachers, prescriptive ideas, onesize-fits-all techniques, fixed and untimely delivery methods, little or no follow-up, decontextualized programs, lack of proper evaluation, pedagogical (child-centered) instruction.

The restructuring of current $\mathrm{CPD}$ schemes into a Community of Inquiry (CoI), which adopts a more reflective and metacognitive approach, may be necessary. With the prevalence of Information and Communications Technology (ICT), a localized, contextual and reciprocal program harnessing collegial support from like-minded professional communities is more feasible than ever. A particular form of technologyenhanced CPD scheme, namely a Massive Open Online Course (MOOC), constructed and operated by Indonesian teachers to mitigate the challenges other local teachers encounter within their day-to-day teaching, is highlighted.

This paper reports the study investigating (1) the challenges teachersface in enhancing their quality as teachers, and (2) the advantages of partaking in an online learning communityto meet such professional demands. These broad research objectives are articulated into the following research questions:

1. What challenges do teachers face in enhancing their quality as teachers?

2. According to the teachers' perception, how does engaging in an online community of inquiryease their professional development? 


\section{Literature Review}

This research stems from the necessity of CPD for teachers as lifelong learners and reflective pedagogical thinkers (Grossman, 1992). Through CPD, teachers as professional beings with authority, autonomy and informed judgment to make decisions in the classroom, transcend beyond being "technicians" who strategize quick fixes for problems without restructuring their views and moral obligations (Day, 1999).

Having received teacher training does not grant any teacher exemption from maintaining high quality. A tendency in teacher education is that student teachers opt for simple and applicable "tips and tricks" although teacher educators do promote more reflective, academic and theoretical approaches (Treagust, Won, Petersen \& Wynne, 2015). Davis, Petish and Smithley (2006) corroborate on the depth of teacher training in that its graduates focus on the somewhat technical-superficial aspects (e.g. classroom management and attention drawing) as opposed to more rudimentary aspects of acknowledging learners' ideas and backgrounds. Another example is how early childhood teachers enter the profession based on the misinterpretation that early childhood teaching is comparable to being able to "handle" children with fun activities,

\section{Teachers' Challenges}

Despite how imperative CPD is, teachers find difficulties to engage in such activity or to reap benefits from following one. The majority of previous research centers on what constitutes an effective program (e.g. Garet, Porter, Desimone, Birman\& Yoon, 2001), yet research highlighting the ob- overseeing other pressing roles, e.g. dealing with parents, instilling values (Mahmood, 2013). Considering the limited pre-service teaching practice, teachers do not fully encounter such interpersonal demands until they enter the profession.

To hone learners' conceptual understanding, teachers need to have in-depth and adaptable knowledge of the field, which could be enhanced through professional development (Borko, 2004). A common issue is that schools not only in Indonesia, but also worldwide, accept under qualified teachers (Treagust et al., 2015). Particularly in Indonesia, schools in rural areas where stringent educational policies are also enforced may have teachers with no educational qualifications, or only high school diplomas (Supriyanti, 2012). Furthermore, when there are opportunities for dialogs with other professionals, CPD lessens the loneliness or isolation in teaching and the stigma for in-service teachers to ask for help (Beltman, Mansfield \& Price, 2011). Miller, Ray, Dove and Kenreich (2000) report that CPD programs involving collective participation encourage teachers to design new learning experiences both for students and their own personal satisfaction.

stacles teachers face in current CPD schemes and how they resolve them is scant. Two issues are worth discussing in examining the challenges in improving professional development: insufficient school support and incapacity to reflect.

Insufficient School Support.An accommodating school administration or a 
supportive principal greatly aids teachers' professional growth (Towers, 2012). A recurrent reason behind why teachers are stagnant or even leave the profession entirely is the lack of support, e.g. the absence or inadequacy of induction program, ongoing CPD scheme or peer-support (Jacob, 2007). Furthermore, commonly practiced CPD schemes are traditional (one-time workshops and irregular trainings) and short on time, activities and relevant content (Birman, Desimone, Porter \&Garet, 2000), lacking competent presenters/trainers for remote areas (Broadley, 2010) or missing the integral factor of feedback/follow-up due to funding (Ingvarson, Meiers, \& Beavis, 2005). Additionally, a shortage of resources, such as laboratories and technology devices hinder teachers' initiative to test out cuttingedge methods they are introduced to in CPD trainings (Tanang, Djajadi, Abu \&Mokhtar, 2014). Towers (2012) also reported that low access to supporting materials exacerbate teachers' reluctance to apply a new curriculum although training is provided.

Incapacity To Reflect.Broadley's study (2010) of teachers in rural areas reveal that professional learning communities for critical self-reflections and sharing with other teachers are invaluable. Avalos (2011) further asserts that co-learning, networking, and exchanges within one school and interschools emulate the natural desire of teachers to talk. Furthermore, when teachers are asked to observe themselves on tape and self-reflect, they were unable to pinpoint their weaknesses thus achieving little skill improvement (Hill, Beisiegel, \& Jacob, 2013). However, teachers' inability to make time to form this "professional learning culture” is a resounding issue due to teachers' heavy workload or personal restrictions (skills, knowledge, other non-teaching responsibilities) (Day, 1999, p.60). In addi- tion, in the case that schools do promote collaborative CPD through mentoring, the trainings or guidelines for respective coaches are often obscure (Rhodes \&Beneicke, 2002). Other cases where mentoring projects are inefficient are due to a clash between trainers and trainees' teaching beliefs or routines as a result of unclear mentoring protocols (Barrett, Jones, Mooney, Thornton, Cady, Guinee, Olson, 2002).

This review of past research shows a constant tug-of-war between school's attempts to conduct CPD and teachers' expectations or capabilities. Therefore, the present research investigating how teachers mitigate such situations is worthwhile.

\section{Technology enhanced CPD to ease pro- fessional challenges}

To mitigate the limited opportunities to reflect and connect to professional learning communities, we recommend engaging teachers in context-specific regional projects with direct contribution to problems in their individual setting. This form of CPD derives from "teacher inquiry", involving a reciprocal flow between curriculum objectives, institutional needs, local factors including the needs and responses of learners, and the wider professional networks and communities. A metacognitive approach, or "learning to learn” needs to be adopted (Phelps, Graham, \& Kerr, 2004), i.e., CPD workshops need to consider teachers' existing knowledge. Program goals and achievement are self-regulated rather than imposed - teachers should recognize, express and follow goals independently. A prevailing impediment in the design of CPD is that teachers within a school possess inadequate knowledge of their colleagues' current skills and expectations (Smeed\&Jetnikoff, 2016). By contrast, teacher inquiry catalyzes localized or context bound projects bearing direct relevance, i.e., enhanced teacher professionalism and 
fruitful learning processes in the classroom (Tondeur, Forkosh-Baruch, Prestridge, Albion \&Edirisinghe, 2016).

Information and Communications Technology (ICT) may serve as a medium to support reflective and metacognitive CPD. Web-based tools and e-learning platforms have proliferated, allowing selfdirected learning, yet offering collaboration opportunities, and collegial feedback from professional communities, independent of time and distance (Koutsodimou\&Jimoyiannis, 2015). A prevalent model of technology-based CPD is the Massive Open Online Course (MOOC).

One particular type of MOOC is cMOOCs: openly accessible designated platforms for course management grounded in the tenets of constructivist learning (Ji\& Cao, 2016). This MOOC strand compiles educational resources and materials in a structured fashion to foster self-regulated learning, time management, networking, collaboration, and exchange of ideas (Koutsodimou\&Jimoyiannis, 2015). Technically MOOCs are designed to form communities of inquiry encompassing three elements: Cognitive, Social and Teaching presences (Garrison, Anderson, \& Archer, 2001, 2010) (see Fig 1).Dewey's Practical Inquiry Model (1933)underlies the Cognitive Presencein CoI progressing from phases, namely:progressing from phases, namely: (a) triggering event, (b) exploration, (c) integration, and (d) resolution (see Fig 2). Learners do not experience these four phases as distinctive or linear, but rather they immerse in a recursive-reiterative process of reflection and meaningful communication with others to assimilate ideas and consolidate comprehension (Swan, Garrison, \& Richardson, 2009). When the participants are presented with a triggering event (derived from a contextualized issue or problem), they are encouraged toenter the exploration stage to brainstorm feasible solutions through collegial interaction. Whereas in face-tofaearrangements, the constraints of time and location may deter people from geographically by harnessing rigorous collaborativedistant places to gather and explore solutions, the online learning community enables time and space-dependent collaboration. To this end, learning communities may exploit time-unbound asynchronous, including discussion threads, emails, wikis, or real-time synchronous means, such as chatting and video-conference (Sari, 2012).

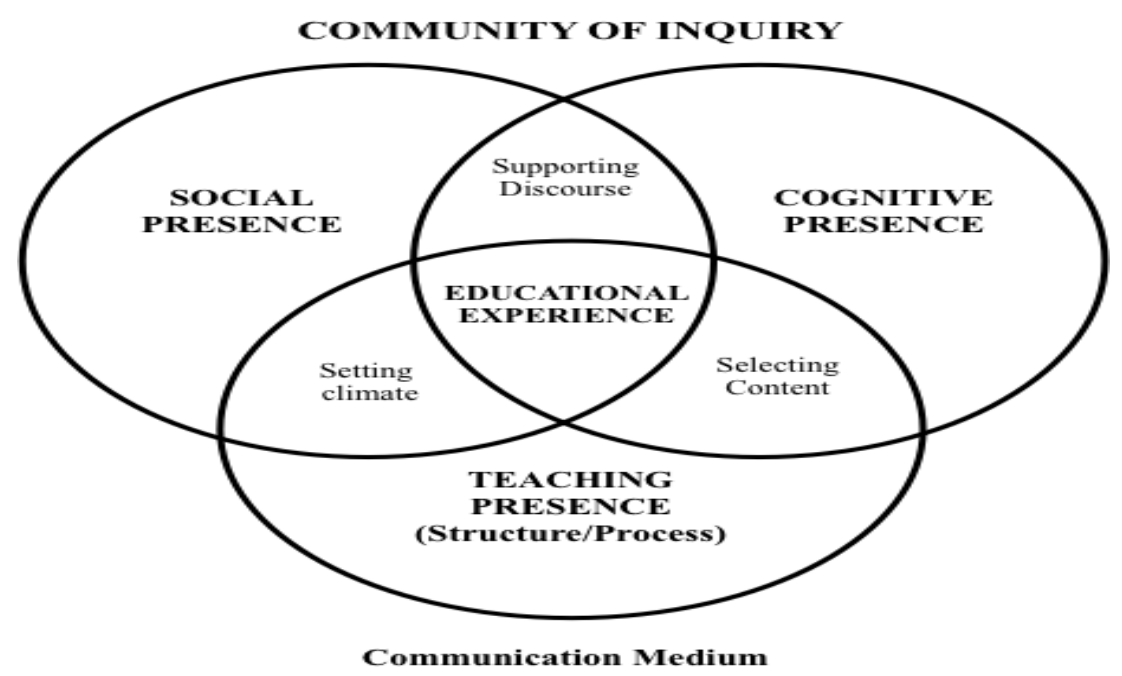

Fig. 1:Community of Inquiry framework (Garrison, Anderson, \& Archer, 2000, p.2, 
2010, p. 6)

Upon formulating the concept in the exploration phase, participants would be able to discern the reasoning behind the issue at hand, and thus integrate new concepts reflection, which suppresses the sense of isolation teachers often face within the profession (Tondeur, Forkosh-Baruch, Prestridge, Albion, \& Edirisinghe, 2016). Furthermore, it is through this stringent
Cognitive Presence in the community of inquiry that participants hone their metacognition (Akyol \& Garrison, 2011). Through the repetitive and dialogic acts of elaborating ideas, raising questions, clarifying meaning, deducing and proposing solutions, participants' ability to evaluate and justify their thought process is enhanced.

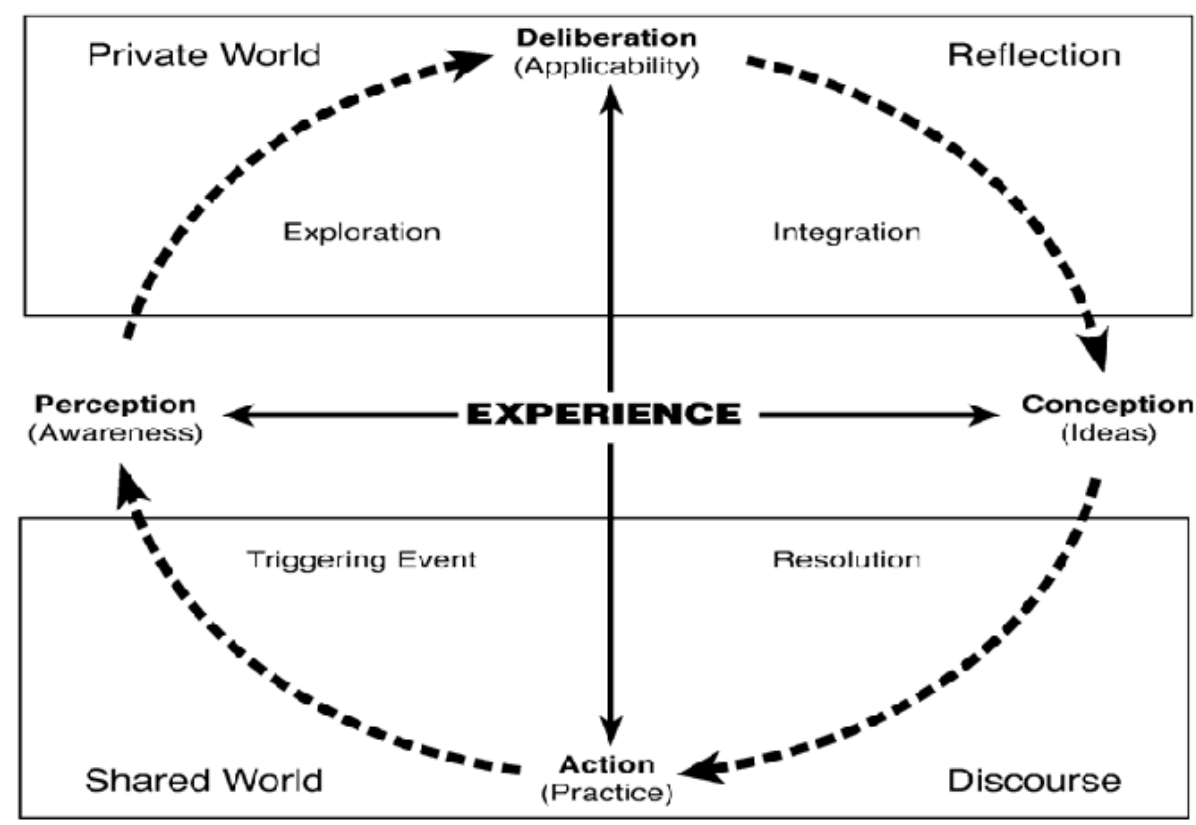

Fig 2: Practical Inquiry Model(Garrison, Anderson, \& Archer, 2001, p. 23)

The Teaching Presence is evident in the presence of instructor's scaffolding for participants to gauge major concepts, the pedagogically strategic compiling and structuring of learning resources, and purposeful task design. The Social Presence is promoted so that learners may relate to the course collective goal and develop a sense of self-entitlement. Furthermore, the social perspective of CoI is primarily characterized by the occurrence of purposeful and transparent communication in a supportive online medium governed by netiquettes. Specifically, the indicators of "affective expression” for freer production of personal ideas and ideologies, "open communication" to set and nurture a shared goal, and "group cohesion" to ensure purposeful communication aimed at the completion of learning activities, should be observable in a CoI(Swan et al., 2009, p. 10). An example of a fine-tunedCPD scheme is the series of online interactive short-courses operated by NASA (National Aeronautics and Space Administration) Office of Education and the NASA Explorer Schools Project, U.S. Satellite Laboratory, Inc. for science teachers. From a mixed-methods analysis, the course is perceived as an invaluable professional development resource with a particularly 
attractive feature, i.e. the chance to connect with like-minded professionals without the financial and time burden of traveling (Marrero, Woodruff, Schuster, \& Riccio, 2010). Reflecting the social constructivist approach, the participants were able to construct their knowledge together.

The IMOOC as a viable CPD tool.The teachers of the foundation under studywereoffered to enroll in the Indonesian MOOC (IMOOC), the first MOOC tailor-made for Indonesian teachers' local needs, managed by the Regional English Language Office (RELO), U.S. Embassy Jakartain collaboration with fifteen national universities (see Fig 3). Through a Learning Management System (LMS) called Canvas, the 2018 iteration of IMOOC focuses on promoting "autonomous learning through the use of digital tools”, through an approximately 3-month long set of modules. The module topics range from comprehending digital literacy, creating quizzes and infographics to using videos to improve self-directed practice of English language skills and components.

The three most commonly observed features of an effective CPD program are: (1) a balanced coverage of both content and pedagogical knowledge, (2) a platform for social constructivist learning, and (3) school support (de Kramer, Masters, O’Dwyer, Dash, \& Russell, 2012). The first criterion is achieved in that IMOOC aimed at exposing participants to cutting-edge teaching paradigms with consideration of direct classroom application. This is realized through the provision of feedback from facilitators (senior teachers or lecturers with relevant educational backgrounds) on the feasibility and correct staging of their activity or lesson plans. The second indicator is evident in the voluntary and somewhat competitive admission process. Since more favorable outcomes can be expected when participants have entitlement to select the programs or CPD to take part in (Smeed\&Jetnikoff, 2016), the participants' initial motivation level or stance toward the program had been taken into account. These teacherparticipants were screened and hand-picked based on their motivational statements. Consequently, this pre-requisite led to only two (2) teachers from the current study partaking in the IMOOC. Satisfying the third requirement, through written invitation letters, IMOOC administrators issued formal invitation letters, and face-to-face meetings for the schools housing the respective participants. 


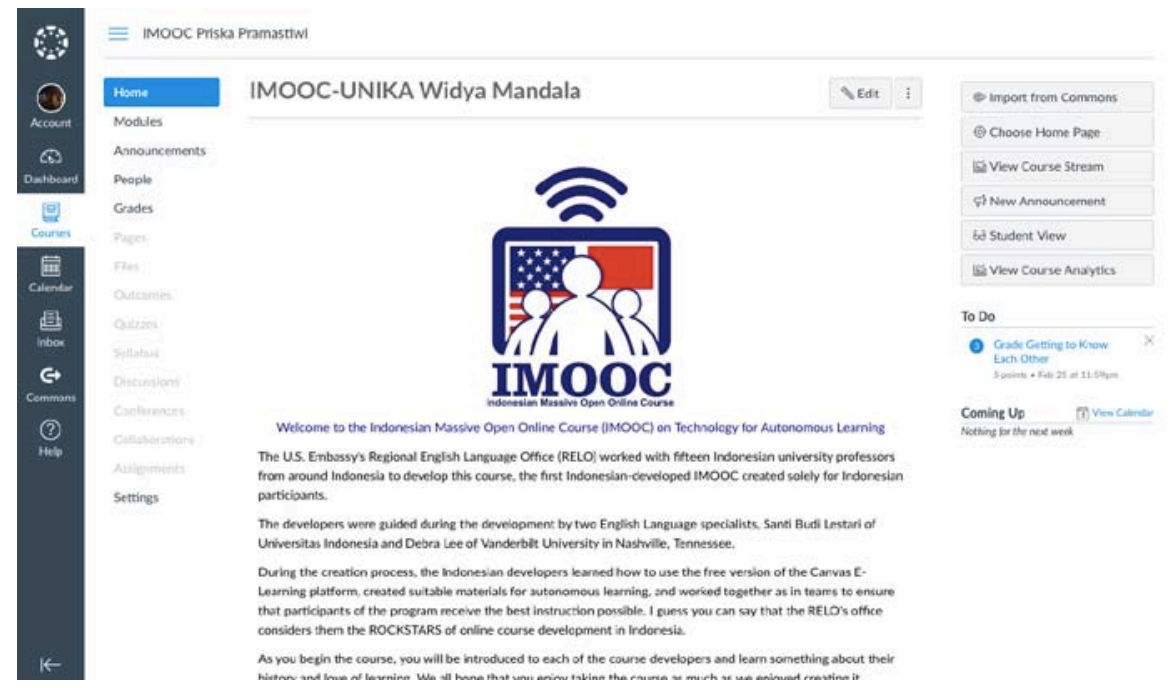

Fig 3: IMOOC 2018 Homepage on Canvas

Although the current IMOOC theme is most advantageous for language teachers, the course' theoretical framework applies in other content fields. In achieving the Cognitive Presence, following Dewey's Practical Inquiry (1933), material delivery panned out according to the structure of (a) triggering event, (b) exploration, (c) integration, and (d) resolution. Upon receiving new concepts, participants underwent some confusion prompting them to exchange and connect ideas with peers, before implementing them in pedagogical solutions to fit local needs. Throughout this cognitive engage- ment, the Teaching Presence is of utmost importance to provide facilitation and direction. Prior to the course, this facilitative presence is embodied through selecting proper learning resources and designing tasks. The Social Presence is met through forming a sense of belonging and a shared goal among the course members. Ultimately, with course members originating from more than 30 different institutions nationwide, the IMOOC enables its participants to receive more extensive feedback and insights from likeminded professionals.

\section{Methods}

It has come to our attention that biographical inquiries describing in-service challenges, and resources teachers leverage in their professional development are scant. Firstly, stemming from narrative inquiry, this research explores teachers' challenges in their CPDfromwritten pedagogical and professional stories or reflective essays, followed by semi-structured interviews.Subsequent to their involvement in the technology-enhanced CPD, perception surveys were administered to analyze whether participation in a MOOC had posi- tively addressed the professional challenges frequently encountered.

\section{Contexts and participants.}

The subjects of the study are fifteen (15) teachers under a private school foundation in Surabaya, Indonesia, which oversee various educational levels from kindergarten up to senior high school. The school foundation has designed and implemented a comprehensive continuing professional development program that includes a system of career ladder for all their full-time teachers, a competency-based assessment, a series of training modules, and a mentoring system. 
Teachers work through a grading level from Grade 7 through Grade 16. In every grade, they participate in a series of training activities designed specifically for each grade. In addition, novice teachers are assigned to enhance their professional journey with a mentor. After a minimal period of two years, they are entitled to go through a competency-based assessment for a chance of promotion to the next grade level.

To focus on significant voices that describe their insights on their professional journey, we narrowedour in-depth analysis to fifteen (15) teachers-five teachers in each of their professional development stages (novice, mid-career, and senior). The same teachers were offered to take part in an online community of inquiry (CoI) through the IMOOC, but only two teachers was finally admitted into the program.

\section{Data collection.}

To collect the data, the researchers first developed guiding questions and protocols of the recorded semi-structured interview. Semi-structured interviews were conducted due to theflexibilityof forwarding follow-up questionsbased on the preceding responses.
Within 30 - 40 minutes in the interview, the researchers tried to probe some aspects of the research topic in depth. Following this, the researchers developed reflective essay prompts for each level of professional development and gave teachers four weeks to write their essays. Subsequently, the teachers were offered to take part in a MOOC to supplement their current practices and aid the recurrent hurdles they face in carrying out their professional duties. Upon completion of the IMOOC, a brief survey was administered to shed light on whether such technology-mediated CPD were relevant for their individual teaching contexts.

\section{DataAnalysis.}

The data collected from the documents, semi-structured interview and a brief satisfaction survey were analyzed qualitatively. The written notes of interview were transcribed, categorized and compiled together into themes and translated into English. Ultimately, the teachers' reflective essays, interview transcript, and survey responses were coded into related themes to reveal patterns for further interpretation (Miles, Huberman, \& Saldana, 2014).

\section{Findings and Discussion}

Whether a teacher remains in the teaching profession withstandingphysical or mental exhaustion causing workplace burnout may be affiliated with how they overcome daily challenges and enhance their professional capability. Therefore, this study places in-service demands and professional development on a continuum regulating the tools and resources teachers rely on in upgrading competence, and retaining within the profession.

\section{TheChallenges}

Time-manage ment.Comparable to fellow teachers worldwide, participants face various challenges ranging from students' problems, classroom management issues, and time management. Time management pose as a predominant hindrance since teaching responsibilities subsume administrative duties, namely,lesson planning and writing reports. Teacher 13'elaborates this tall order in the following reflective essay excerpt:

The part of my job that I need to improve on is my time management -howto allocate time for planning my lessons, arranging the learning activities and teaching process, designing the assessment procedures, aside from leaving time for selfevaluation and development. What usually 
happens is that I only have time at home or on the weekends for personal development. I am often occupied with handling student affairs, not only those under my responsibility, but also the incidental ones(Teacher 13, reflective essay).

Similarly, Teacher 7testifies that the magnitude of the teaching load (correcting and organizing clubs) truncates his personal time outside working hours:

... Consequently, as I have beenassigned to be the captain of the Boys' Brigade in addition to being a homeroom teacher, I basically relinquished any chances of personal development. I no longer have time to read or update on current teaching techniques, as I have to continue working on my school-related duties at home(Teacher 7, reflective essay).

Teacher 9 echoes the urgency of proper time management, which also extends to time allocation during classroom hours. She perceives the need to design purposeful classroom activities to strike a balance between assessment procedures and student amusement during the learning experiences.

Because of time limitation, it is sometimes impossible to cover all the enjoyable activities. There are so many score that I have to collect such as, the English test, writing test, speaking test, listening test and the practices in the students' books. I have to beat the time so my students will enjoy when they learn English by doing many activities. I have to arrange the schedule well. Sometimes I fail, but I still need to work on it(Teacher 9, reflective essay).

Pertaining tonovice teachers, in addition to adjusting with unfamiliar school facilities, routines, policies and procedures, they need to fulfill similar duties as experienced workers, which is not the case in other professions(Farrell, 2016).Farrell also asserts that for teacher education graduates, a common misconception is that they merely need to apply what they've learned in college or their 3-month up to 1-year teaching assistantship. The reality is far more complex with the first five years in the teaching career as the most crucial period. Previous studies reveal $24 \%$ of novice teachers terminating their profession in the first year, $33 \%$ after three years, and 40\% - 50\% withdrawing before the fifth year. Posing as a transition shock, unlike their senior counterparts, these novice teachers do not have the luxury of time and accumulated skills they can rely on to navigate through such challenges. To illustrate, Teacher 12, revealed how the pressures of being a novice teacher had influenced her emotional wellbeing, which ultimately affected her teaching performance.

Since entering the profession in the year 2008, I have endured difficult circumstances. In the first term, facing students in class for the first time amidst the incoming consecutive deadlines drove me to panic and stress. In turn, it caused my emotional stability to deteriorate. My productivity levels at that moment were below standard (Teacher 12, reflective essay).

For those graduating from noneducation majors or without an initial desire to teach, adapting to the school environment and work ethics had placed a strain on the decision to remain in the profession. As voiced by Teacher 2, a senior teacher, the onset of her career was a series of momentous pivotal moments to either redirect or remain steadfast in this professional course. With the help of her parents who were also educators, she was able to overcome the hardships of the adaptation process and construct her own vocational identity, despite the absence of intrinsic motivation. On this note, perhaps owing to Indonesia's collectivist culture and socioeconomic constraints, 
the findings concur thelikelihood of becoming teachers if one's parents are also teachers. In other words, the chance of choosing to teach as a career is positively associated with the approval of parents and friends (OzturkAkar, 2012; Byun\& Park, 2017; Padhy, Emo, Djira\&Deokar, 2015).

My late parents encouraged me to be a teacher although it wasn't my personal choice to become one. During my first years in the profession, I did feel awkward, overloaded and incapable to meet the demands. However, my parents urged me to persevere. That is why not everyone is called to teach (Teacher 2, reflective essay).

After dedicating 12 years in the field of education, in the case of a senior teacher, Teacher 10, she admits the need to replenish her teaching style, which in her opinion has been rather archaic. In her essays, she reflects on this necessity to be accustomed to using ICT to improve the learning process.

I need to start making use of digital media and technology, preferably through e-learning. I would say that with the help of technology, I will be able to use my time and energy more efficiently. The delivery of information will also be more systematic with the archiving function - enabling students to access my materials regardless of time and place (Teacher 10, reflective essay).

Teacher 14 finds affinity to this concern as, being a senior teacher himself, he is sentient towards the attrition of students engagement in classroom activities. With the ability to access a plethora of information in just a few taps on a smartphones, it is imperative for teachers to design relevant pedagogically sound activities.

One of the things that lead students to construct their understanding is a meaningful activity. Keeping students busy doing something meaningful is a challenge for all teachers (Teacher 14, interview transcript).

To exemplify how technology proficiency would be an invaluable skills in teachers' repertoire, a novice teacher with less than 5 years teaching experience maintained a sense of achievement when she resorted to technology to cope with the lack of preparation time. The CALL class in preservice training had particularly aided the laborious task of media preparation.

In college I took a course on CALL (Computer-assisted Language Learning), especially for making flash-based media. It has helped me a lot in my everyday teaching. (Teacher 11, novice, interview transcript).

Limited access to external professional communities. Almost all the teacher participants in this study acknowledged the availability of a supportive working environment (Van Droogenbroeck, Vrije\&Vanroelen, 2014; Bick-har, 2012). The school system has provided a comprehensive professional development system that meets the professional needs of these teachers. As part of the induction program, the new recruits are put under a mentoring system whereby mid-career and senior teachers are assigned to supervise and guide them. Apart from trainings and performance evaluations, teachers also participate in regular religious services such as fellowships and devotions. As voiced by Teacher 4, experts from locally or internationally renowned organizations deliver such trainings:

The trainings from ACSI [Association of Christian Schools International] and Mathematics MGMP [Musyawarah Guru Mata Pelajaran, Subject Teachers Club] organized by the school board after a Morning Service ... inspiration from the Cambridge assessment ... reflection after each lesson ... 
readiness to be engaged in trainings or seminars ... lots of colleagues, be open to criticism; always be open to other teachers who want to observe my class ... be a mentor for younger teachers ... between mentor and mentee, can establish rapport based on learning goals for both of us ... I, too can learn from my mentees (Teacher 4, reflective essay).

As Gorozidis and Papaioannou (2014) suggest, a combination of professional autonomy, competence, personal relevance and collegial support promoted in the work environment would yield a sense of loyalty to the school and teachers' mental well being. This notion is relevant for Teacher 2, who came into the profession without any teaching qualifications or educational background, and thus, faced 'unexplored territory':

I remember the words of my coordinator, Pak Samual, during my first years of teaching. He said that a lot of people become teachers, but they don't have the soul of one. So it is better for those with nonteaching degrees to teach if they have the right intentions. That's what has kept me motivated until now. My co-workers also kept assuring me that it's okay if my educational background is not linear, as long as I'm willing to learn(Teacher 2, interview transcript).

Novice and mid-career teachers showed a similar pattern, namely, they sought for guidance and affirmation from senior teachers. Similarly, senior teachers expressed appreciation for the professional development system including the mentoring program, which has evolved and improved over the years. They believed teachers in their school were fortunate to have the level of support to enhance their professional development within their school system, which include induction, a series of training for different levels of teachers, supervision, teacher evaluation, and mentoring. The effect of a collaborative school environment could also transcend to a personal sense of achievement in shaping the success of other fellow teachers, as expressed by Teacher 3 . She maintained:

I have been a mentor since 2014. In relation to my position as a vice-principal, I am happy to share my triumphs or failures in teaching to my mentee based on the reason that we all need to be students. Failure doesn't deter us from being an educator when we are able to learn from the positives to improve (Teacher 3, interview transcript).

Only a small minority of the participants sought support from resources outside of their school system. It was fleetingly mentioned that teachers referred to books, website and the intention to pursue further education. This reliance on the school foundation to facilitate professionalism may mean that the current CPD is comprehensive enough to meet professional needs. Contrastively, participants may be toocomplacent in their convenient school environment to rely on their devices, thus, succumb to the temptation of groupthink tendencies. This occurrence may be viewed as "vulnerability towards the outside world"-teachers may feel that they are under the watchful eye and scrutiny of the school management, colleagues and parents (Kelchtermans, 1993). Teachers are wary of the fact that not only do they need to see an impact of their teaching on the students' achievement (evidence of self efficacy), but they also need to build good relationships or rapport with the students. However, in achieving this, at times, parents and the school board may question what teachers view as professionally sound. As in the words of Kelchtermans, "teachers can only rely on their reflective experience, intuition, and their professional commitment 
in trying to defend their professional behavior and to convince others of its value" (1993, p. 454). As a result, teachers become passive and conservative the more vulnerable they become. This may be observed in Teacher 9's essay excerpt revealing that she is conscious of the need to consultadditional input elsewhere, yetacknowledge the tendency to be passive.

A great lesson plan is the lesson plan that give the students a clear idea of what they will do so I have to read more and more about any kind of activities that I can do and suitable for my students. This is not easy because I have to beat my laziness (Teacher 9, reflective essay).

This vulnerability to the school authorities also relates with a previously mentioned finding that many of the participants settled on their teaching careers as safer options, possibly to make ends meet. It can be assumed that a lack of prospective opportunities in the job market may deter some teachers from pursuing other careers (Bickhar, 2012). Furthermore, at the time of recruitment, teachers of this foundation are offered a very satisfactory reward package, which is more attractive than that in most other schools in town. It is common for recent graduates to resort to teaching for its perceived benefits, such as career security and salary, or relatively low demands of the job (Sinclair, 2008). This lack of resilience at the initial stage of their professional development might still linger, trap them in a comfort zone, and keep them from moving forward in their professional trajectory.

With the highly structured mentoring scheme, imposed top-down trainings (albeit offered by teacher associations), and absence of personal drive, it can be assumed that the participants have little to no exposure to contrive wider professional relations or peer-networking with others from differ- ent schools.Hargreaves (2000) divides teacher professionalism into four stages of development: the pre-professional age, the age of the autonomous professional, the age of the collegial professional and the fourth age - the age of post-professional or postmodern. The participants of the study can be considered as autonomous professionals whereby they have the freedom--and even encouraged--to design their syllabi and deliver their materials in creative ways. However, the third phase of collegial professional is yet to be introduced, as teachers need to be engaged further in professional circles and communities of collegial professionals outside their school system.

Online Community of Inquiry and Their Professional Development?

Integration of new concepts for more effective teaching practice. With generally positive reviews of the IMOOC graduates, it may be inferred that, despite the exhaustive 3-month long duration and strenuous program deadlines, teachers are willing to devote time in establishing a community of inquiry on the condition that it presents applicable practices or instantaneous gains (Holmes, 2013). The IMOOC participants, including those taking part in the current study, confirmed the ease of integrating the digital tools into their syllabus and everyday teaching. Grounded by the "teacher inquiry" or metacognitive approach, a "cascade of knowledge" effect was evident to contend with the isolation teachers may endure in the teaching profession.Teaches were urged to experiment multiple techniques to incorporate technology into their projects, as well as respond to other's sharing of best practices (Tondeur et al., 2016). As expressed by Teacher 6, there has been a significant shift in awareness and perspective since before partaking in the course as evident in the following excerpt: 
Previously, I knew little about application, learning sources, or pay little attention on mobile learning and the significance of its use for teaching-learning process. However, since I joined this course, I realize that learning activities are able to take a new face, a new experience by utilizing technology. Considering the 21 century skills and global demands for more collaboration in the process of learning, IMOOC plays its role as the excellent course which qives chances and challenges for teachers or education practitioners to be aware of the needs of involving students more in the learning process and give novel horizon

Common to CPD structures, revitalizing teaching habits requires effort and time confronting institutional or technical hindrances. However, this metacognitive concept adopted by IMOOC encourages the assembling of support groups or networks, increasing teachers' participation and commitment to improve outside of the CPD initiative (Phelps et al., 2004). From the survey, the teachers reported to have successfully managed to circulate impactful concepts, information or practices to their fellow colleagues (47.05\% maintained a strong about the process of engaging students to be more active, self-managed, autonomous, and responsible towards their participation in the program (IMOOC Participant, survey response)

From 17 participants who responded to the survey, two of which are taking part in the current study, a vast majority expressed a strong agreement to being able to repurpose the digital tools to afford learning process, which cannot be obtained from a more traditional approach - i.e., 35.29\% citing a strong agreement, and 58.82\% moderately agreeing (see Table 1).

agreement) despite being hindered by unstable Internet connection and insufficient provision of devices (64.71\% cited a mild agreement). This is inline with Gruba and Hinkelman (2012) who laud the benefits of incremental and sustainable change in teaching procedures. Therefore, teachers in the IMOOCare not applying the techniques introduced in this form of CPD simply because they can(which leads to a mere abrupt change), but instead making informed decisions weighing both benefits and drawbacks. The following is a survey response

Table 1

Perception on IMOOC Relevance to Individual Teaching Context

\begin{tabular}{|c|c|c|c|c|c|}
\hline Survey Statements & $\begin{array}{l}\text { Strongly } \\
\text { Disagree }\end{array}$ & Disagree & $\begin{array}{c}\text { Neither } \\
\text { Agree nor } \\
\text { Disagree }\end{array}$ & Agree & $\begin{array}{c}\text { Strongly } \\
\text { Agree }\end{array}$ \\
\hline $\begin{array}{l}\text { I was able to integrate the ma- } \\
\text { terials, concepts or digital tools } \\
\text { introduced in IMOOC in my } \\
\text { own classroom. }\end{array}$ & $5.88 \%$ & $0.00 \%$ & $0.00 \%$ & $58.82 \%$ & $35.29 \%$ \\
\hline
\end{tabular}

I encountered obstacles (either technical or institutional) that hampered the application of $0.00 \% \quad 0.00 \% \quad 29.41 \% \quad 64.71 \% \quad 5.88 \%$ the digital tools in my everyday teaching. 
I was able to overcome technical or institutional hindrances that inhibited the integration of the digital apps in $\begin{array}{lllll}0.00 \% & 5.88 \% & 23.53 \% & 70.59 \% & 0.00 \%\end{array}$ my classroom.

I managed to share what I found beneficial from the IMOOC materials or suggested $0.00 \% \quad 0.00 \% \quad 0.00 \% \quad 52.94 \% \quad 47.06 \%$ digital tools to my colleagues.

from one of IMOOC participants heralding a successful experience dabbling with one of the suggested digital tool, while taking into account possible limitations:

"I found the success whenever I integrated Quizlet, Edpuzzle and Orai in my class By using EdPuzzle, I could manage my time better whenever I prepare the video material and present that material in class Quizlet too, I found it as the great app to practice their vocab outside the class in fun way. I ever got a response too from my students whenever I integrated Quizlet talk in class. They said it is fun way to learn and memorize since they were actively calling the targeted vocabulary and by also talking / communicating the new entry vocabs in various way at class with peers, it decreased their anxiety whenever they tried to speak in English because they did not hesitate and they were not shy to practice even though they pronounced some vocabs wrong and used inaccurate sentences ... I could not guarantee that all of them are learning the vocabulary via Quizlet independently at home, at least we have provided the suitable vocab activity outside the class to support their English learning activity." (IMOOC Participant, survey response)

Opportunities to form professional network. A frequent positive remark rendered upon program completion is the essence of collegial support permeating throughout the course iteration. This is consistent with Smeed and Jetnikoff (2016, p.119) who laud the benefits of embedding "professional reflection and collegial discussion" in CPD schemes to achieve sustainability.Mostparticipants cited that "meeting new people and sharing with them", "the togetherness in all of the project assigned", or "great friends, new input" as the driving force behind successful knowledge construction. One particular survey respondent commended the opportunity to band together with others of similar interests to support advancement within the teaching profession: ..., I experienced great things during the program. I can have new network which is later, I believe, fruitful for my profession as lecturer. Besides, IMOOC gives new perspectives about online learning. Although I do not prefer online learning to be whole method being implemented in the classroom, the idea of blended learning isquite effecti$\underline{v}$ in order to give students chance to increase their motivation and improve their skills(IMOOC Participant, survey response).

It is interesting to note that being a lecturer, with ideally more educational expertise than the majority of the participants who did not pursue postgraduate study, he/she still admitted the benefits of the joint enterprise built. This implies that within the collective unit, there were no clashing power relationships or identity issues strong enough to cause low rapport or apprehension to cooperate with others (Murugaiah, Ming, Azman, \& Nambiar, 2013). In other words, this CPD scheme attempts to coa- 
lesce the cultural contextwiththe group dynamics, assigned responsibility and communal goal (Liu, 2012). However, the use of contrastive conjunction (although) and hedging (quite effective) may direct to the corollary that even though this CPD program has endowed new insights for practice, resistance may delay the immediate change in perspective(Macià\& García, 2016).

To decipher why participants mainly referred to the collaborative aid as an attractive CPD feature, the researchers revisited the discussion threads. The high level of diversity imbued in the online exchange suggests that the educators drew on their individual belief system as well as their teaching context. As can be seen in the discussion posts (Fig 4 and Fig 5), the participants felt comfortable enough to disclose their authentic personalities and perspectives irrespective of power positions of hierarchical constraints within the community of educators or academics (Lee \& Brett, 2015). This presence of heteroglossic dialogs characterized by opposing opinions and meaning negotiations (see underlined expressions in Fig 4 and Fig 5) contributed to a high level of discussion, which contained collegial support (e.g. I do agree with...) coupled with criticism (e.g. I would like to give some objection and support)(Prestridge, 2010). The discussion threads in Fig 4 and 5 are also indicative of a metacognitive process that is facilitated by a community. Metacognition underlie the act of formulating, elaborating, and justifying opinions. Although the individual bears responsibility to derive meaning from the materials, the community in turn may offer varied perspectives or pinpoint a possible error in the personal conception (Akyol \& Garrison, 2011). It is opined that the standardized onesize-fits-all CPD program, such as wholeclass one-off trainings and seminars, may not be able to accommodate such diversity(Lee \& Brett, 2015).

\section{Post comment:}

Dear Bu Elisa,

\section{You are right up to a point.}

I do agree with your last paragraph of the first statement of your 1st answer. $\underline{\text { However, }}$ in my view, the autonomous learners will gradually be able to adapt to the materials they choose by themselves, not be given by the teacher. Because of their own choices, so the righteousness and meaningful materials will be their responsibility now which could raise their awareness of the future approaches and appropriate learning opportunities.

Thank you.

Best regards,

Natasha

$$
\text { Reply: }
$$

(...)Thank you for the correction, Ms. Natasha. Actually what I meant by the given materials there are the main topics that the students should learn during that semester, such as the one written in the RPP. Just imagine that during the first week, the students should be able to master Algebra. The students are then provided by lists of subtopics that they can choose by themselves and some options of the quiz type they want to take. (...)

Fig 4: A snippet of the discussion thread in one of the modules 
Hi Naomi,

\section{Post comment:}

Well, I would like to give some objection and support related to your statement that autonomous students are gifted students. In my opinion, being autonomous in learning does not naturally come out from one's own. It should done through well preparation and lots of practices. (...)

Reply:

Hi Fiona,

Thanks for such a thorough review. But I'd like to point out that I never suggest in any way that autonomous learners ARE gifted students, I simply wonder if the students in the video are gifted students because they seemed so smart being able to run the class so autonomously. (...)

Fig 5: A snippet of the discussion thread in one of the modules

In tandem with iteration of the online course, a social media group was constructed for the participants to interact outside of the Canvas page. Utilizing the group chat on Whatsapp, the participants frequently exchanged classroom ideas, concerns and updated news pertaining to the IMOOC progress. For instance, Fig 4 showcases a remark of excitement and pride upon incorporating Quizlet in the teacher-participant's class. In this particular chat thread, the participant shared a photo to other IMOOC participants exhibiting how engaged his students were in his vocabulary lesson augmented by the referred digital tool. The social presence (Garrison, Anderson \& Archer, 2001, 2010) was achieved in this instance through the collegial support and reciprocal encouragement contributing to a collaborative atmosphere.

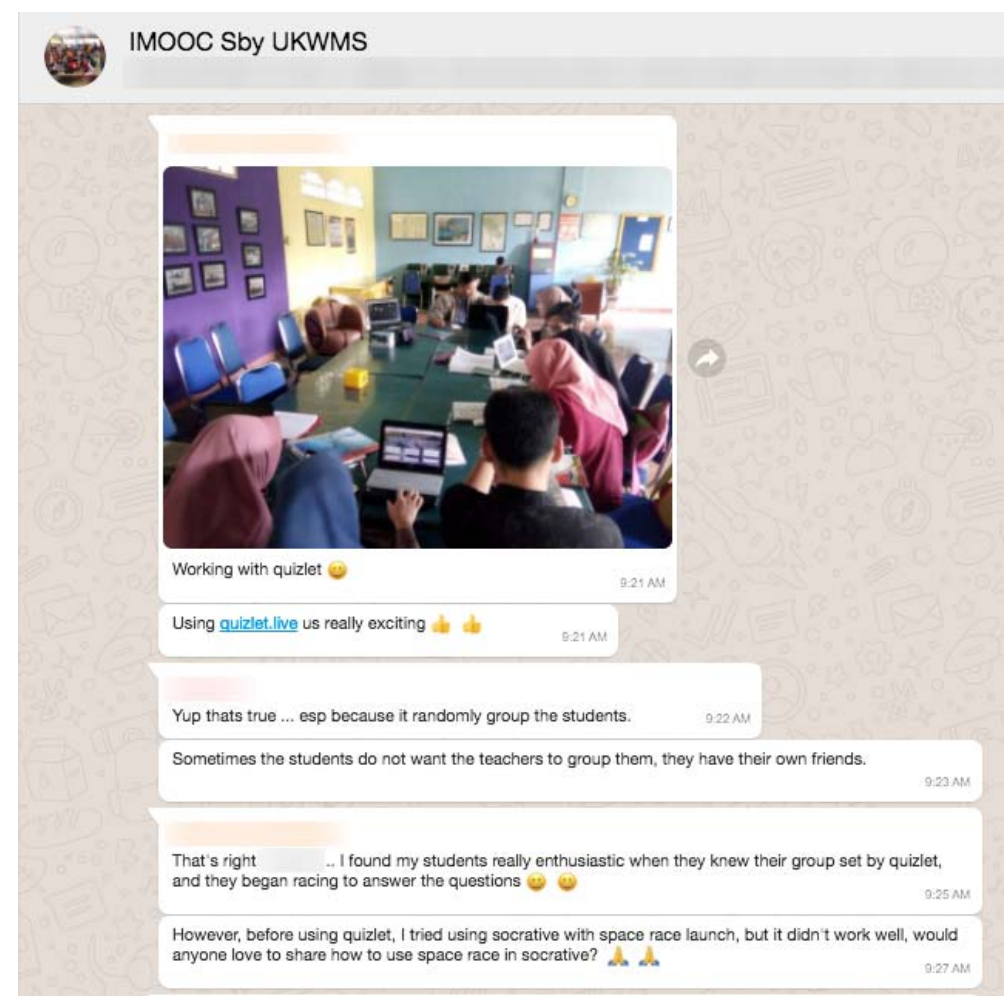

Fig 4: Whatsapp Chat Thread between IMOOC Participants 


\section{Conclusion}

With the divergentinitial motivationto teach, prior experiences and level of resilience, teachers may experience isolation, and low urgency to expand their collegial networks. To supplement school-managed programs, regional MOOCs may serve as efficient means to form professional communities within a purposeful and cognitive- ly stimulating scheme, bearing immediate value to individual context. Although retention and relevance of such a program is yet to be examined, the reflective-collaborative online environment is integral to what constitutes a desirableCPD that ismetacognitive teacher inquiry. 


\section{References}

Akyol, Z., \& Garrison, D. R. (2011). Assessing metacognition in an online community of inquiry. Internet and Higher Education, 14(3), 183-190. http://doi.org/10.1016/j.iheduc.2011.01. 005

Avalos, B. (2011). Teacher professional development in Teaching and Teacher Education over ten years. Teaching And Teacher Education, 27(1), 1020.http://dx.doi.org/10.1016/j.tate.2010. 08.007

Barrett, J., Jones, G., Mooney, E., Thornton, C., Cady, J., Guinee, P., \& Olson, J. (2002). Working with Novice Teachers: Challenges for Professional Development. Mathematics teacher education and development, 4, 15-27.

Beltman, S., Mansfield, C., \& Price, A. (2011). Thriving not just surviving: A review of research on teacher resilience. Educational Research Review, 6(3), $185-$

207.http://dx.doi.org/10.1016/j.edurev.2 011.09.001

Birman, B. F., Desimone, L., Porter, A. C., \&Garet, M. S. (2000). Designing professional development that works. Educational leadership, 57(8), 28-33.

Bick-har, L. (2018). Why Do They Want to Become Teachers? A Study on Prospective Teachers' Motivation to Teach in Hong Kong. The Education University Of Hong Kong, 21(2), 307-314.

Borko, H. (2004). Professional Development and Teacher Learning: Mapping the Terrain. Educational Researcher, 33(8),

15.http://dx.doi.org/10.3102/0013189x0 33008003

Broadley, T. (2010). Digital revolution or digital divide: Will rural teachers get a piece of the professional development
pie?.Education in Rural Australia, 20(2), 63.

Byun, S., \& Park, H. (in press). When a young student wants to be a teacher: Cross-national differences in 15-yearold students' expectations of becoming a teacher. In M. Akiba\& G. LeTendre (Eds.), Routledge International Handbook of Teacher Quality and Policy. Routledge.

Chang, M. C., Shaeffer, S., Al-Sammarrai, S., Ragatz, A. B., de Ree, J., \& Stevenson, R. (2014). Teacher reform in Indonesia.

Choi, P., \& Tang, S. (2009). Teacher commitment trends: Cases of Hong Kong teachers from 1997 to 2007. Teaching And Teacher Education, 25(5), 767777.

http://dx.doi.org/10.1016/j.tate.2009.01. $\underline{005}$

Czerniawski, G. (2011). Emerging teachersemerging identities: Trust and accountability in the construction of newly qualified teachers in Norway, Germany, and England. European Journal of Teacher Education, 34(4), 431-447.

Davis, E., Petish, D., \&Smithey, J. (2006). Challenges New Science Teachers Face. Review Of Educational Research, 76(4), 607-651. http://dx.doi.org/10.3102/00346543076 004607

Day, C. (1999). Developing teachers. London: Falmer Press.

deKoning, L. (2012). Coaching the transition towards developmental education: Exploring the situation with teachers. In Developmental Education for Young Children (pp. 189-205). Springer, Dordrecht.

de Kramer, R. M., Masters, J., O’Dwyer, L. M., Dash, S., \& Russell, M. (2012). 
Relationship of Online Teacher Professional Development to SeventhGrade Teachers' and Students' Knowledge and Practices in English Language Arts. Teacher Educator, 47(3), 236-259. http://doi.org/10.1080/08878730.2012.6 85795

Dewey, J. (1933). How we think (revised). Boston: DC Health.

Diaz-Maggioli, G. (2014). Tradition and habitus in TESOL teacher education. Language and Linguistics Compass, 8(5), 188-196.

Ebersöhn, L. (2015). Making sense of place in school-based intervention research. Contemporary Educational Psychology, 40, 121-130.

Farrell, T. S. C. (2016). Surviving the transition shock in the first year of teaching through reflective practice. System, 61, 12-19. http://doi.org/10.1016/j.system.2016.07 .005

Garet, M., Porter, A., Desimone, L., Birman, B., \& Yoon, K. (2001). What Makes Professional Development Effective? Results From a National Sample of Teachers. American Educational Research Journal, 38(4), 915-945. http://dx.doi.org/10.3102/00028312038 $\underline{004915}$

Garrison, D. R., Anderson, T., \& Archer, W. (2000). Critical Inquiry in a Text-Based Environment:InComputer Conferencing in Higher Education. The Internet and Higher Education, 2(2-3), 87-105.

Garrison, D. R., Anderson, T., \& Archer, W. (2001). Critical thinking, cognitive presence, and computer conferencing in distance education. American Journal of Distance Education, 15(1), 7-23. http://doi.org/10.1080/08923640109527 071
Garrison, D. R., Anderson, T., \& Archer, W. (2010). The first decade of the community of inquiry framework: A retrospective. Internet and Higher Education, 13(1-2), 5-9. http://doi.org/10.1016/j.iheduc.2009.10. 003

Gorozidis, G., \&Papaioannou, A. (2014). Teachers' motivation to participate in training and to implement innovations. Teaching and Teacher Education, 39,

$1-11$. http://dx.doi.org/10.1016/j.tate.2013.12. $\underline{001}$

Grossman, P. (1992). Why Models Matter: An Alternate View on Professional Growth in Teaching. Review Of Educational Research, 62(2), 171. http://dx.doi.org/10.2307/1170579

Gruba, P. \&Hinkelman, D. (2012). Blending technologies in second language classrooms. Palgrave Macmillan.

Hargreaves, A. (2000). Four ages of professionalism and professional learning. Teachers and Teaching: Theory and Practice, 6(2), 151-182.

Hill, H., Beisiegel, M., \& Jacob, R. (2013). Professional Development Research: Consensus, Crossroads, and Challenges. Educational Researcher, 42(9), 476-487.

http://dx.doi.org/10.3102/0013189x135 $\underline{12674}$

Holmes, B. (2013). School Teachers' Continuous Professional Development in an Online Learning Community: lessons from a case study of an e Twinning Learning Event. European Journal of Education, 48(1), 97-112. http://doi.org/10.1111/ejed.12015

Ingvarson, L., Meiers, M., \& Beavis, A. (2005). Factors affecting the impact of professional development programs on teachers' knowledge, practice, student 
outcomes \& efficacy. Education Policy Analysis Archives, 13, 10. http://dx.doi.org/10.14507/epaa.v13n10 $\underline{.2005}$

Jacob, B. (2007). The Challenges of Staffing Urban Schools with Effective Teachers. The Future of Children, 17(1), $129-$ 153.http://dx.doi.org/10.1353/foc.2007. 0005

Ji, Z., \& Cao, Y. (2016). A Prospective Study on the Application of MOOC in Teacher Professional Development in China. Universal Journal of Educational Research, 4(9), 2061-2067.

Kelchtermans, G. (1993). Getting the story, understanding the lives: From career stories to teachers' professional development. Teaching and Teacher Education, 9(5-6), 443-456. http://doi.org/10.1016/0742051X(93)90029-G

Kelchtermans, G., \&Vandenberghe, R. (1994). Teachers' professional development: a biographical perspective. Journal of Curriculum Studies, 26(1), 45-62. http://dx.doi.org/10.1080/00220279402 $\underline{60103}$

Koutsodimou, K., \&Jimoyiannis, A. (2015). MOOCs for teacher professional development: investigating views and perceptions of the participants. In Proceedings of the 8th International Conference of Education, Research and Innovation-ICERI 2015 (pp. 69686977).

Lee, K., \& Brett, C. (2015). Dialogic understanding of teachers' online transformative learning: A qualitative case study of teacher discussions in a graduate-level online course. Teaching and Teacher Education, 46, 72-83. http://doi.org/10.1016/j.tate.2014.11.00
1

Liu, K. Y. (2012). A design framework for online teacher professional development communities. Asia Pacific Education Review, 13(4), 701-711. http://doi.org/10.1007/s12564-0129230-0

Mahmood, S. (2013). First-year preschool and kindergarten teachers: Challenges of working with parents. School Community Journal, 23(2), 55.

Macià, M., \& García, I. (2016). Informal online communities and networks as a source of teacher professional development: A review. Teaching and Teacher Education, 55, 291-307. http://doi.org/10.1016/j.tate.2016.01.02 1

Marrero, M. E., Woodruff, K. A., Schuster, G. S., \& Riccio, J. F. (2010). Live, Online Short-Courses: A Case Study of Innovative Teacher Professional Development. International Review of Research in Open and Distance Learning, 11(1), 81-95. http://doi.org/10.3102/0013189X03300 8003

Miles, M. B., Huberman, A. M., \& Saldana, J. (2014). Qualitative data analysis: A method sourcebook. CA, US: Sage Publications.

Miller, S. L., Ray, S., Dove, T., \&Kenreich, T. (2000). Perspectives on personal professional development. Collaborative reform and other improbable dreams: The challenges of professional development schools, 141.

Murugaiah, P., Ming, T. S., Azman, H., \& Nambiar, R. (2013). Is Presence of Community of Practice Dimensions Sufficient for Community-Based Teacher Professional Development? International Journal of Web-Based Learning and Teaching Technologies, 
$8(1)$,

32-45.

http://doi.org/10.4018/jwltt.201301010

3

OzturkAkar, E. (2012). Motivations of Turkish Pre-service Teachers to Choose Teaching as a Career. Australian Journal of Teacher Education,37(10). http://dx.doi.org/10.14221/ajte.2012v37 $\underline{\mathrm{n} 10.7}$

Padhy, B., Emo, K., Djira, G., \&Deokar, A. (2015). Analyzing Factors Influencing Teaching as a Career Choice Using Structural Equation Modeling. SAGE Open, 5(1), $\quad 215824401557039$. http://dx.doi.org/10.1177/21582440155 70393

Phelps, R., Graham, A., \& Kerr, B. (2004). Teachers and ICT: Exploring a metacognitive approach to professional development. Australasian Journal of Educational Technology, 21(1), 49.

Prestridge, S. (2010). ICT professional development for teachers in online forums: Analysing the role of discussion. Teaching and Teacher Education, 26(2), 252-258. http://doi.org/10.1016/j.tate.2009.04.00 4

Rhodes, C. \&Beneicke, S. (2002). Coaching, mentoring and peer-networking: challenges for the management of teacher professional development in schools. Journal of In-Service Education, 28(2), 297-310. http://dx.doi.org/10.1080/13674580200 200184

Sari, E. R. (2012). Online learning community: A case study of teacher professional development in Indonesia. Intercultural Education, 23(1), 63-72. http://doi.org/10.1080/14675986.2012.6 64755

Schleicher, A. (2015). Schools for 21stCentury Learners: Strong Leaders,
Confident Teachers, Innovative Approaches. International Summit on the Teaching Profession. OECD Publishing. 2, rue Andre Pascal, F-75775 Paris Cedex 16, France.

Sinclair, C. (2008). How can what we know about motivation to teaeh improve the quality of initial teacher edueation and its practieum? In. In P. Towndrow, C. Koh\& T. Soon, Motivation and practice for he classroom (pp. 37-61). Rotterdam, Netherlands: Sense.

Smeed, J., \&Jetnikoff, A. (2016). Lessons to be learnt from two professional development programs. Leading and Managing, 22(1), 105.

Supriyanti, N. (2012). Challenges in Providing Trainings for English Teachers of Elementary Schools. Journal of Education And Learning (Edulearn), 6(3), 161.

http://dx.doi.org/10.11591/edulearn.v6i 3.159

Swan, K., Garrison, D. R., \& Richardson, J. C. (2009). A constructivist approach to online learning: The community of inquiry framework. Information Technology and Constructivism in Higher Education: Progressive Learning Frameworks, 43-57. http://doi.org/10.4018/978-1-60566654-9.ch004

Tanang, H., Djajadi, M., Abu, B., \&Mokhtar, M. (2014). Challenges for Teachers in Developing their Teaching Professionalism: A Case Study of Secondary School in Makassar, Indonesia. Journal of Education and Learning (Edulearn), $8(2)$ 132.http://dx.doi.org/10.11591/edulearn .v8i2.215

Tondeur, J., Forkosh-Baruch, A., Prestridge, S., Albion, P., \&Edirisinghe, S. (2016). Responding to Challenges in Teacher

Beyond Words Vol.6 No.2 (2018) 
Professional Development for ICT Integration in Education. Educational Technology \& Society, 19 (3), 110120.

Towers, J. (2012). Administrative supports and curricular challenges: New teachers enacting and sustaining inquiry in schools. Canadian Journal of Education, 35(1), 259-278.

Treagust, D., Won, M., Petersen, J., \& Wynne, G. (2015). Science Teacher Education in Australia: Initiatives and Challenges to Improve the Quality of Teaching. Journal of Science Teacher Education, 26(1), 81-98. http://dx.doi.org/10.1007/s10972-0149410-3

Van Droogenbroeck, F., Spruyt, B., \&Vanroelen, C. (2014). Burnout among senior teachers: Investigating the role of workload and interpersonal relationships at work. Teaching And Teacher Education, 43, 99-109. http://dx.doi.org/10.1016/j.tate.2014.07. $\underline{005}$

Walter, C., \& Briggs, J. (2012). What professional development makes the most difference to teachers. A report sponsored by Oxford University Press. 